\title{
Possible hidden cause of human immunodeficiency virus type 1 latency and role of interferon
}

\author{
N Ahmed ${ }^{1}, \mathrm{~K}$ Miura $^{2}$
}

\begin{abstract}
Latent human immunodeficiency virus type 1 (HIV-1) infected cells under antiretroviral therapy are reported to be resting memory CD4+ T cells; however, the mechanisms of HIV-1 latency is unclear. We demonstrate that long-term culture of interleukin-2-dependent CD4+ T cells with a memory phenotype mimicked latently HIV-1-infected cells in the presence of interferon- $\alpha$. These cells are mostly resting and contained HIV-1 proviruses that could be re-activated by stimulation. Our findings suggest a potential role of type-1 interferon in HIV-1 latency.
\end{abstract}

Key words: HIV-1 latency, interferon, CD4+ T cells.

\section{Introduction}

Highly active antiretroviral therapy (HAART) efficiently suppresses human immunodeficiency virus type 1 (HIV-1) replication and improves the prognosis of HIV-1 infection. ${ }^{1-3}$ Interruption of HAART leads to rebound in viremia, because antiviral drugs can only limit the active viral replication but not eliminate latently infected cells. ${ }^{4-7}$ As a result, lifelong antiretroviral therapy is required for infected individuals. This is accompanied by various side effects including a heavy financial burden, because of the cost of treatment. It would be advantageous to determine how latently HIV-1-infected cells can be eliminated in vivo.

In HIV-1-infected individuals after long-term HAART, latent HIV-1-infected cells remaining in peripheral blood were reported to be resting memory type CD4+ T cells. They exhibit a CD4+ CD45RA- CD45RO+ HLA-DR- phenotype and possess integrated HIV-1 provi- ruses that do not replicate unless activated. $4,6,8$ However, it is not well understood how HIV-1 persists in cells under latent conditions.

In the present study, we attempted to reproduce HIV-1 latency in memory CD4+ T cells that had been cultured for a long period and whose growth is dependent on antigen stimulation. We also examined the effects of type-1 interferon (IFN- $\boldsymbol{\alpha}$ ) on HIV-1 latency. The $\boldsymbol{\alpha}$ IFNs are produced by many kinds of cells in vivo even in physical conditions as well as in HIV-1-infected individuals and known to restrict viral replication and induce cell cycle arrest in peripheral blood mononuclear cells (PBMCs). ${ }^{9-13}$ The aim of the present study was to identify possible hidden cause of HIV-1 latency and role of IFN.

\section{Materials and Methods}

We isolated CD4+ CD25- CD45RO- T cells from PBMCs of a healthy individual using 
immunomagnetic beads. The cells were then stimulated with beads coated with anti-CD3 and -CD28 antibodies (CD3/CD28 beads, Invitrogen) for 5 days in the presence of 10 $\mathrm{nM}$ all trans retinoic acid (ATRA), $50 \mathrm{U} / \mathrm{ml}$ interleukin (IL)-2 and $5 \mathrm{ng} / \mathrm{ml}$ transforming growth factor (TGF)- $\beta$, and further cultured in the same medium for three weeks, then maintained in medium containing IL-2 and TGF- $\beta$ for more than 5 months, periodically stimulated with CD3/CD28 beads. The resulting CD4+ $T$ cell line was designated the LTiT4 (long term inducible T cell positive for CD4) line.

\section{Results and discussion}

LTiT4 cells exhibit a memory $T$ cell phenotype (CD45RA-CD45RO+ CD27+ CD127+)

(Fig.1A). Stimulation with CD3/CD28 beads strongly induced CD25 expression (Fig. 1B) and tumor necrosis factor-alpha (TNF- $\boldsymbol{\alpha}$ ) production in LTiT4 cells (Fig. 1C). Thus, LTiT4 cells are non-tumor memory-type CD4+ $T$ cells that can be maintained in the presence of IL-2 and proliferate in response to antigen stimulation.

We assessed the effects of IFN- $\alpha$ on LTiT4 cells (Fig 2A). The cell growth rate of LTiT4 cells was diminished by IFN- $\alpha$ in a dosedependent manner at concentrations of 300 and $1000 \mathrm{U} / \mathrm{ml}$. IFN- $\boldsymbol{\alpha}$-treatment markedly reduced expression of CD25, while the CD45RA- CD45RO+ HLA-DR- phenotype was not largely altered irrespective of IFN- $\boldsymbol{\alpha}$ treatment (Fig. 2B). Through cell cycle analysis, we observed that the majority of LTiT4 cells at 2 and 4 weeks after stimulation were

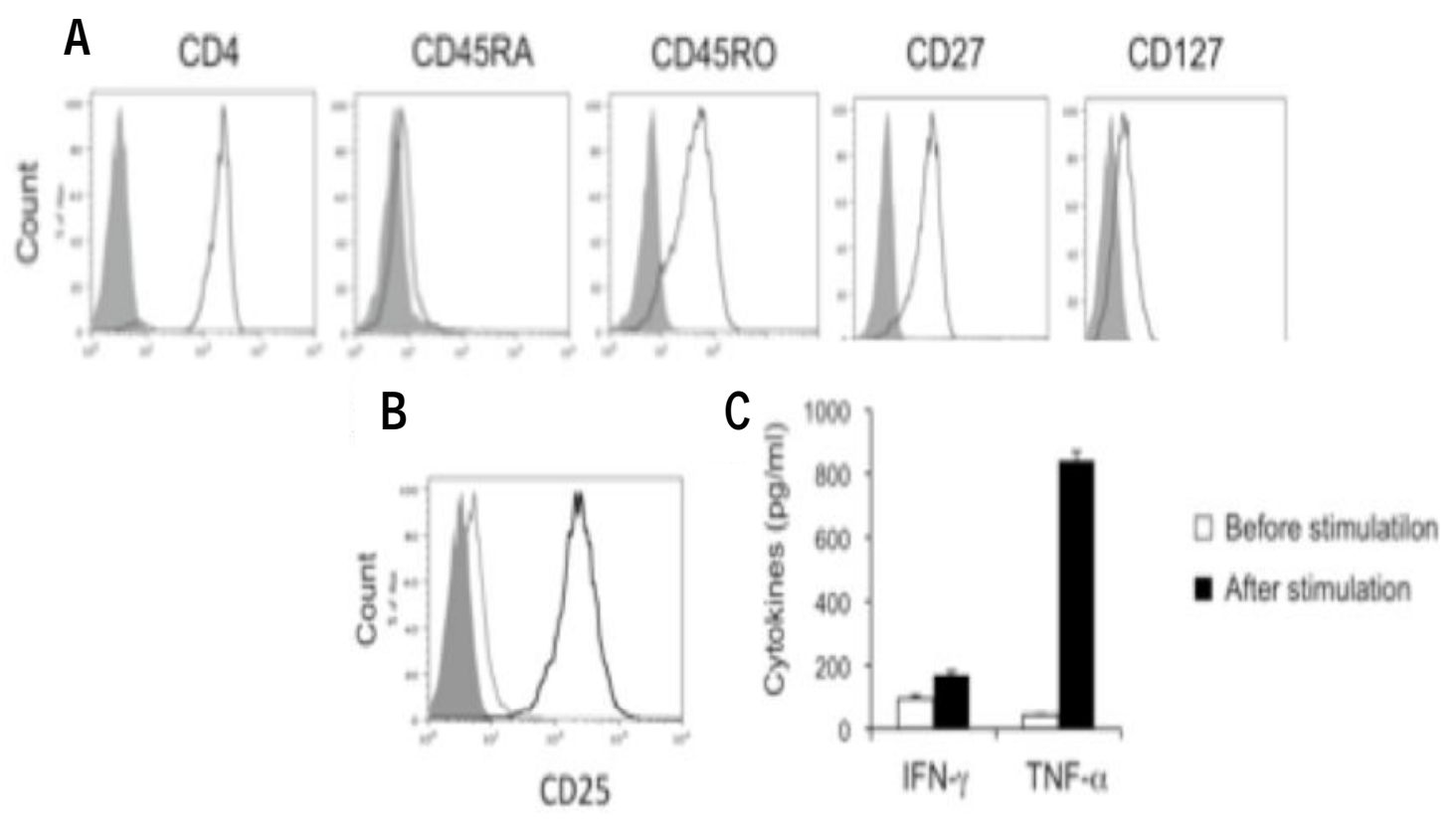

Fig. 1. A. Cell surface phenotype of LTiT4 cells in the resting stage was evaluated by flow cytometry following staining with FITC conjugated CD4, CD27 (Biolegend), CD127, CD45RO, and CD45RA (BD Bioscience) (lined histogram). Closed histrogram indicates control stained with isotype antibody. B. Cell surface CD25 expression in LTiT4 cells with (dark line) or without (light line) CD3/CD28 beads stimulation for $24 \mathrm{~h}$. C. IFN- $\gamma$ and tumor necrosis factor-alpha (TNF- $\alpha$ ) in the supernatants of LTiT4 cells without (blank bar) and with (closed bar) CD3/CD28 beads stimulation for $24 \mathrm{~h}$ were analyzed by using Th1/Th2 11 plex Kit (eBioscience). 
A

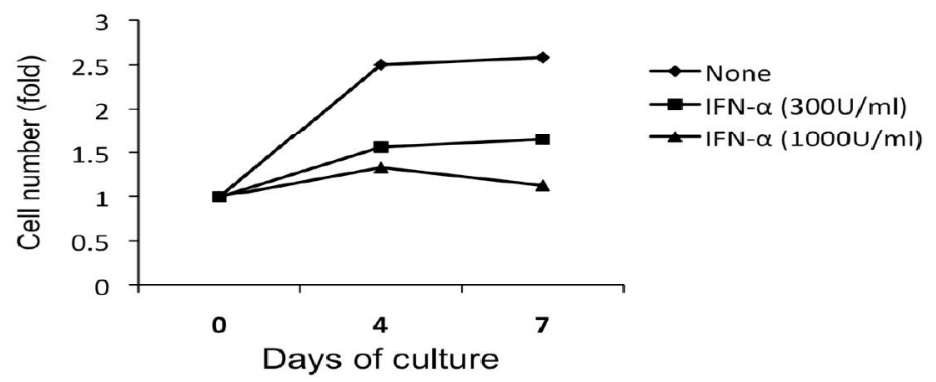

B

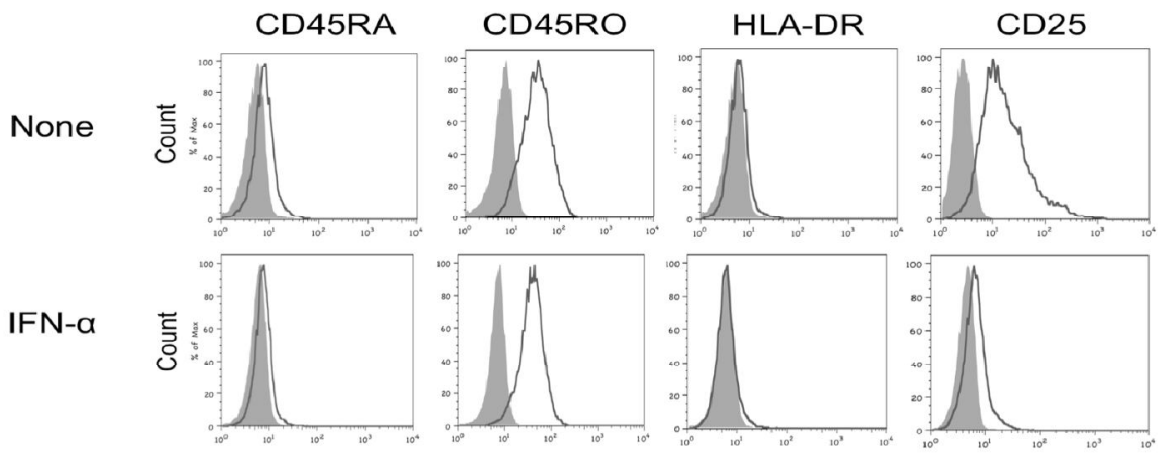

C
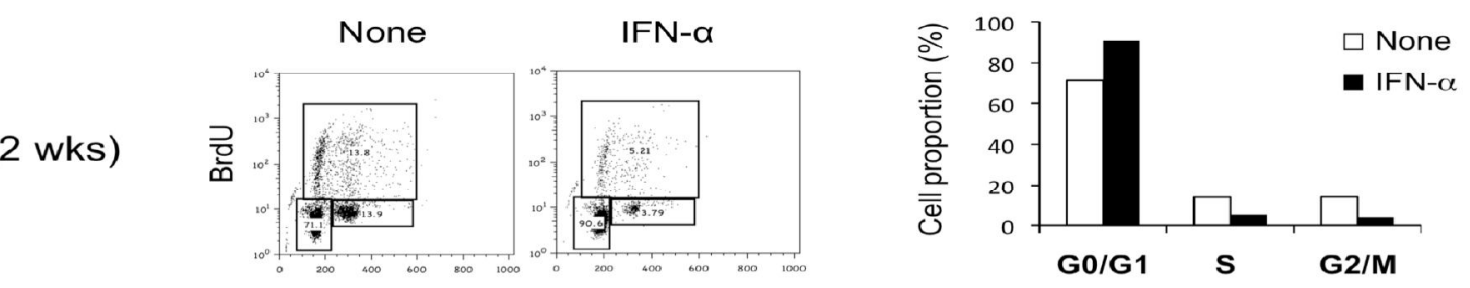

(4 wks)
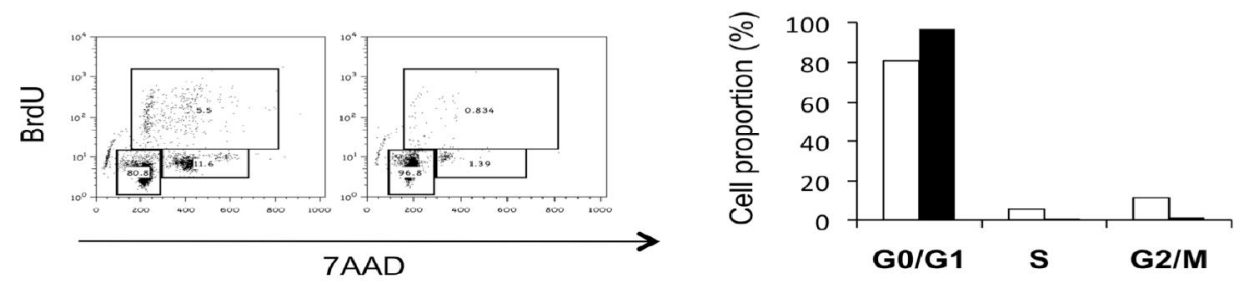

Fig. 2. A. LTiT4 cells were pre-stimulated with CD3/CD28 beads for 3 days, then cultured in the presence of $0(\diamond), 300(\square)$ and $1000(\Delta)$ U/ml of IFN- $\alpha$, and the growth of the cells was evaluated. B. LTiT4 cells were cultured in the presence or absence of $1000 \mathrm{U} / \mathrm{ml}$ IFN- $\alpha$ and the cell surface phenotype on day 14 was analyzed by flow cytometry. Closed histogram indicates isotype control. C. LTiT4 cells in (B) were cultured for a longer period with medium replenished once a week. Cells were subjected to cell cycle analysis after 2 and 4 weeks in culture. The results of flow cytometry (left panels) were indicated also in the bar graphs (right panels), with (closed bar) or without (open bar) IFN- $\alpha$. 
A
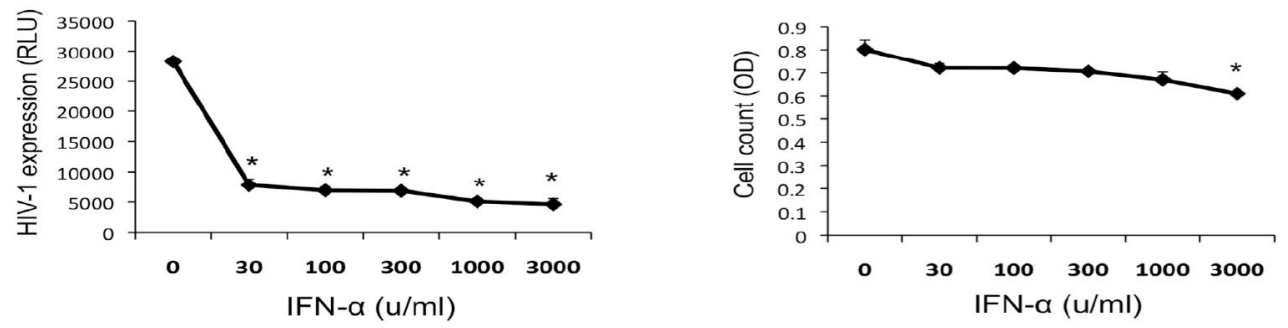

B

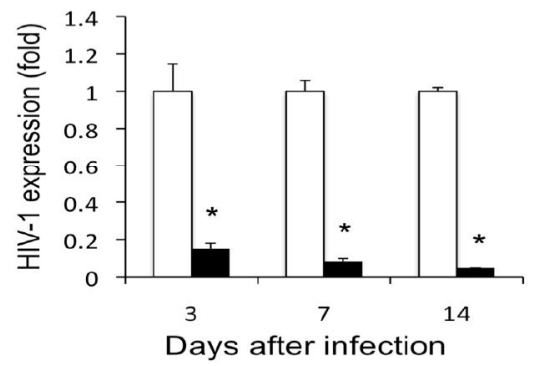

C

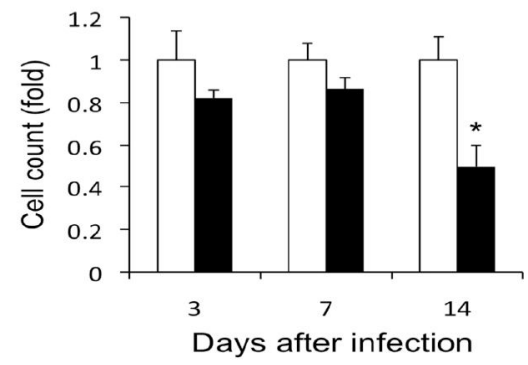

D

E
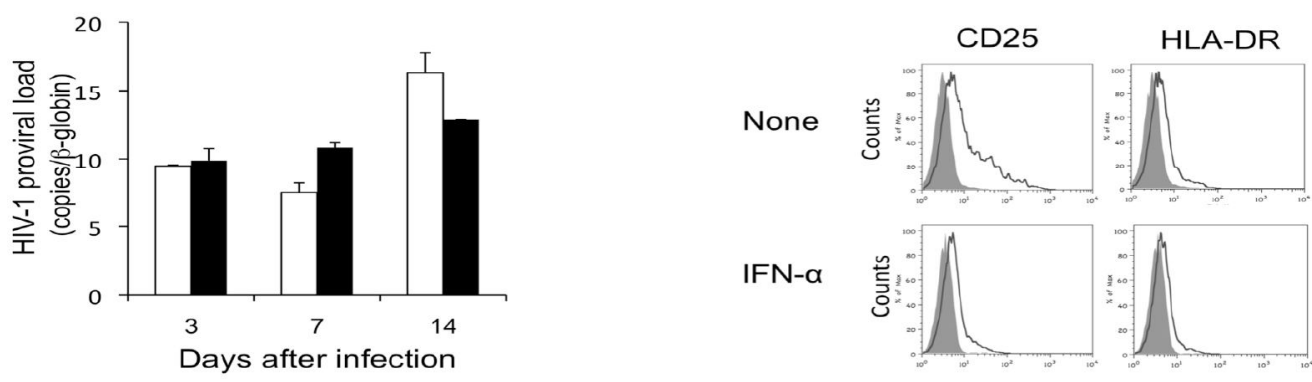

Fig. 3. A. LTiT4 cells at 3 days after stimulation were infected with VSV-G/pNL4-3Luc pseudotype virus (100 ng of HIV-1 p24/10 cells) ${ }^{14}$ overnight in the presence of 100 $\mathrm{U} / \mathrm{ml} \mathrm{IL}-2$. The cells $\left(10^{5} /\right.$ well) were incubated for another day after wash, then treated with various concentrations of IFN- $\alpha$ for 3 days. HIV-1 expression (left panel) and viable cell number (right panel) in each well was evaluated by a luciferase assay and a colorimetric cell counting method, respectively. B-D. LTiT4 cells infected with VSV-G/pNL4-3Luc in the presence (closed bar) or absence (open bar) of $1000 \mathrm{U} / \mathrm{ml}$ IFN- $\alpha$ were subjected to analysis of luciferase activity (B), viable cell number (C) and the amount of HIV-1 proviral DNA (D) at 3, 7, and 14 days post-infection. For B and $\mathrm{C}$, the relative values to the sample without IFN- $\alpha$ for each time points are indicated as the mean and standard deviation. To quantify proviral DNA, chromosomal DNA were subjected to quantitative PCR with R/Gag primer set. E. LTiT4 cells were infected with VSV-G/pNL4-3Luc and cell surface CD25 and HLA-DR expression was evaluated after 14 days of culture in the presence or absence of IFN- $\boldsymbol{\alpha} .{ }^{*}: p<0.05$ (Student's $t$-test). 


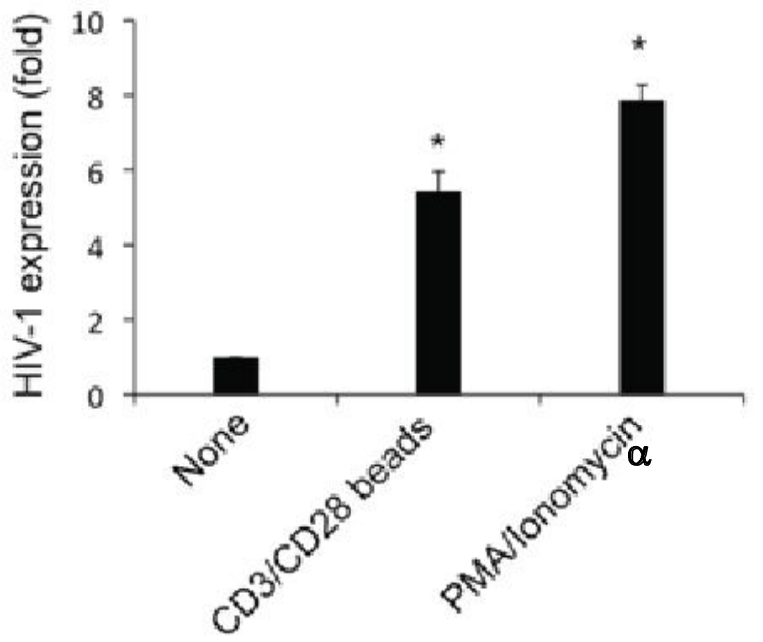

Fig. 4. LTiT4 cells were infected with VSVG/pNL4-3Luc and maintained with $1000 \mathrm{U} / \mathrm{ml}$ IFN- $\alpha$ for 13 days, and $10^{5}$ cells/well were stimulated without or with CD3/CD28 beads (8x104/well), or PMA (50 ng/ml) and lonomycin $(500 \mathrm{ng} / \mathrm{ml})$ for $24 \mathrm{hrs}$, and then subjected to luciferase assays. Relative values against the sample without stimulation were indicated as the mean and SD of duplicate samples. *: $p<0.05$.

already in the G0/G1 phase. Treatment with IFN- $\alpha(1000 \mathrm{U} / \mathrm{ml})$ further increased the numbers of cells in the G0/G1 phase, and decreased those in the $S$ and G2/M phases (Fig. 2C). These findings suggest that IFN- $\alpha$ might accelerate LTiT4 cells entering a resting stage.

We investigated the effects of IFN- $\alpha$ on HIV-1 replication in LTiT4 cells by using a pseudotyped HIV-1 (VSV-G/NL4-3-luc)14 (Fig. 3). The LTiT4 cells well supported HIV-1 gene expression, as determined by luciferase assays. We added different doses of IFN $\boldsymbol{\alpha}$ for 3 days postinfection and found that doses between 30-3000 U/ml significantly suppressed HIV-1 gene expression with a mild dose dependency (Fig. 3A left). Cell numbers were also slightly decreased by IFN- but not significantly except when $3000 \mathrm{U} / \mathrm{ml}$ IFN- $\boldsymbol{\alpha}$ was applied as it was toxic (Fig. 3A right).

Long-term effects were evaluated by maintaining infected cells in the presence or absence of IFN $\alpha(1000 \mathrm{U} / \mathrm{ml})$. The HIV-1 gene expression was significantly suppressed by IFN- $\alpha$ on day 3 and further decreased on days 7 and 14 (Fig. 3B). Cell numbers, as determined by a colorimetric cell-counting kit, were not significantly altered by IFN- $\alpha$ treatment.

HIV-1-infected cells were maintained in cultures with IFN- $\alpha$; we detected HIV-1 proviral DNA in cells on days 3,7 and 14 . Relative copy numbers of HIV-1 proviruses in these cells, standardized with those of $\beta$-globin, were comparable with the cultures lacking IFN- $\boldsymbol{\alpha}$ (Fig. 3D). CD25 expression was reduced by IFN- $\boldsymbol{\alpha}$ as similarly observed in uninfected LTiT4 cells (Fig. 3E). These observations confirmed that, in the presence of IFN- $\alpha$ the HIV-1-infected cells entered a resting stage to a greater extent, and the HIV-1 existed as integrated proviral DNA but was hardly replicate.

Finally, we examined whether immune stimulations could reactivate viral expression in latently HIV-1-infected LTiT4 cells (Fig. 4). We added CD3/CD28 beads into the HIV-1infected LTiT4 cells that were rendered after 2 weeks of culture in the presence of IFN- $\boldsymbol{\alpha}$. At $24 \mathrm{~h}$ post-stimulation, HIV-1 gene expression was significantly enhanced in these cells. Viral expression was also induced by stimulation with phorbol 12-myristate 13-acetate (PMA) and Ionomycin.

Our findings indicated that LTiT4 cells can mimic resting memory $T$ cells in the presence of IFN- $\boldsymbol{\alpha}$, exhibiting post-integration latency following HIV-1-infection. IFN- $\boldsymbol{\alpha}$ seemed to suppress both cell cycle progression and HIV-1 gene expression. There are many reports of type-1 IFN-mediated suppression of HIV-1 replication at the early and late stages of the HIV-1 replication cycle. ${ }^{15-18}$ Additionally, elevation of type-1 IFNs in HIV-1 infected individuals and its undesirable role in acquired immunodeficiency syndrome development by chronic immune activation has been widely debated. ${ }^{19}$ However, little interest has focused on the role of IFNs during HIV latency. Here, we hypothesized a significant role of type-1 IFNs in inducing memory CD4+ $T$ cells towards a resting stage, thereby leading to HIV-1 latency. 
In conclusion, type-1 IFNs induced cell cycle arrest and post-integration latency of HIV-1 infection in memory-type CD4+ $T$ cells derived from a healthy individuals in vitro, mimicking the latently HIV-1-infected resting memory CD4+ $T$ cells detected in HIV-1-infected individuals undergoing HAART. An antigen-specific CD4+ T cell line such as LTiT4 in the presence of IFN- $\boldsymbol{\alpha}$ should be a useful model in understanding the mechanisms of latent HIV-1 infection, and assist the development of novel therapeutic strategies to eradicate latent HIV-1-infected cells.

\section{Acknowledgments}

This work was supported by JST/JICA Science and Technology Research Partnership for Sustainable Development (SATREPS).

\section{References}

1. Cavert W, Notermans DW, Staskus K, et al. Kinetics of response in lymphoid tissues to antiretroviral therapy of HIV-1 infection. Science 1997;276:960-4.

2. Palella FJ Jr, Delaney KM, Moorman AC, et al. Declining morbidity and mortality among patients with advanced human immunodeficiency virus infection. HIV Outpatient Study Investigators. N Engl J Med 1998;338:853-60.

3. Perelson AS, Essunger $\mathrm{P}, \mathrm{Cao} \mathrm{Y}$, et al. Decay characteristics of HIV-1-infected compartments during combination therapy. Nature 1997;387:188-91.

4. Chun TW, Carruth L, Finzi D, et al. Quantification of latent tissue reservoirs and total body viral load in HIV-1 infection. Nature 1997;387:183-8.

5. Tran TA, de Goer de Herve MG, Hendel-Chavez $H$, et al. Resting regulatory CD4 T cells: a site of HIV persistence in patients on long-term effective antiretroviral therapy. PLoS One 2008;3:e3305.

6. Finzi D, Hermankova M, Pierson T, et al. Identification of a reservoir for HIV-1 in patients on highly active antiretroviral therapy. Science 1997;278:1295-300.
7. Finzi D, Blankson J, Siliciano JD, et al. Latent infection of CD4+ $T$ cells provides a mechanism for lifelong persistence of HIV-1, even in patients on effective combination therapy. Nat Med 1999;5:512-7.

8. Wong JK, Hezareh M, Gunthard HF, et al. Recovery of replication-competent HIV despite prolonged suppression of plasma viremia. Science 1997;278:1291-5.

9. Abt MC, Osborne LC, Monticelli LA, et al. Commensal bacteria calibrate the activation threshold of innate antiviral immunity. Immunity 2012;37:158-70.

10. Bocci V. Roles of interferon produced in physiological conditions. A speculative review. Immunology 1988;64:1-9.

11. Lehmann C, Lafferty M, Garzino-Demo A, et al. Plasmacytoid dendritic cells accumulate and secrete interferon alpha in lymph nodes of HIV-1 patients. PLoS One 2010;5:e11110.

12. Ganal SC, Sanos SL, Kallfass C, et al. Priming of natural killer cells by nonmucosal mononuclear phagocytes requires instructive signals from commensal microbiota. Immunity 2012;37:171-86.

13. Zhang F, Sriram S. Identification and characterization of the interferon-betamediated p53 signal pathway in human peripheral blood mononuclear cells. Immunology 2009;128:e905-918.

14. Planelles V, Haislip A, Withers-Ward ES, et al. A new reporter system for detection of retroviral infection. Gene Ther 1995;2:369-76.

15. Pfeffer LM, Dinarello CA, Herberman RB, et al. Biological properties of recombinant alpha-interferons: $40^{\text {th }}$ anniversary of the discovery of interferons. Cancer Res 1998;58:2489-99.

16. Baca-Regen L, Heinzinger N, Stevenson M, Gendelman HE. Alpha interferoninduced antiretroviral activities: restriction of viral nucleic acid synthesis and progeny virion production in human immunodeficiency virus type 1-infected monocytes. J Virol 1994;68:7559-65.

17. Hansen BD, Nara PL, Maheshwari RK, et al. Loss of infectivity by progeny virus 
from alpha interferon-treated human immunodeficiency virus type 1 -infected $T$ cells is associated with defective assembly of envelope gp120. J Virol 1992; 66:7543-8.

18. Shirazi Y, Pitha PM. Alpha interferon inhibits early stages of the human immunodeficiency virus type 1 replication cycle. J Virol 1992;66:1321-8.

19. Herbeuval JP, Shearer GM. HIV-1 immunopathogenesis: how good interferon turns bad. Clin Immunol 2007;123:121-8. role of interferon. Mediscope 2016;3(2):11-7. 